\title{
Mentoring non-traditional students in clinical practicums: Building on strengths
}

\author{
Sherri Melrose* \\ Faculty of Health Disciplines, Athabasca University, Alberta, Canada
}

Received: December 31, 2017

Accepted: February 19, 2018

Online Published: March 1, 2018

DOI: $10.5430 /$ cns.v6n3p39

URL: https://doi.org/10.5430/cns.v6n3p39

\begin{abstract}
Background: As nurse educators respond to increasing numbers of adult learners attending practicum experiences, clinical instructors are one of our richest resources. And yet, the everyday strategies they implement to mentor these non-traditional students towards success may go unnoticed. This article describes findings from a qualitative descriptive research study that listened to the voices of experienced clinical instructors.

Objective: The objective of the study was to describe effective mentoring approaches that instructors in a Post Licensed Practical Nurse to Bachelor of Nursing (Post LPN to BN) program used to support students' learning and build on their strengths during instructor led clinical practicum courses.

Methods: The research was framed from a constructivist worldview and Laurent Daloz's mentoring model. Digitally recorded and transcribed interview data was collected from 10 clinical instructors who had been teaching for more than 5 years. The transcripts were analyzed for themes which were confirmed with participants through member checking.

Results: Findings revealed that instructors supported students by validating individual strengths; challenged them by building on those strengths; and created vision by linking their present activities to competencies needed in their own future practice.

Conclusions: These findings provide valuable insights and guidance to practicing Registered Nurses (RN's) interested in teaching non-traditional students during their clinical experiences.
\end{abstract}

Key Words: Non-traditional students, Post Licensed Practical Nurse to Bachelor of Nursing students, Clinical instructors, Mentoring approaches

\section{INTRODUCTION}

Schools of nursing, like most post-secondary institutions, are experiencing steady growth in the number of non-traditional students attending their programs. ${ }^{[1-5]}$ Non-traditional students, also referred to as mature students or adult learners, are usually over 25 , have delayed their post-secondary enrollment or are returning to their studies, have one or more dependents, attend school part time and are employed full time. ${ }^{[6]}$ Interestingly, since 1996, nearly $70 \%$ of all undergraduate students also possesses at least one of these "non-traditional" characteristics. ${ }^{[6]}$ Many learners attending post-secondary institutions today are juggling responsibilities related to their roles as employees, partners and parents in addition to their roles as students. ${ }^{[3]}$ For many, their educational needs have been neglected, particularly in relation to the limited periods of time they are able to spend away from their employment setting. ${ }^{[7]}$

For non-traditional nursing students, practicum experiences, where attendance at clinical sites for consecutive days and weeks at a time is required, can be especially challeng-

*Correspondence: Sherri Melrose; Email: sherrim@athabascau.ca; Address: Faculty of Health Disciplines, Athabasca University, Alberta, Canada. 
ing. ${ }^{[8-10]}$ Yet, it is often their practicum experiences that most help adult students become socialized into a new professional nursing role ${ }^{[11]}$ and to re-imagine their professional identities in new ways. ${ }^{[12]}$ Mentoring approaches that experienced clinical instructors believe are effective can make an important difference to these students, but they are seldom disseminated beyond individual educational institutions.

Existing research provides direction for mentoring adult learners during their experiences in higher education in general, ${ }^{[13-17]}$ as well as for mentoring different groups of student nurses. ${ }^{[18-21]}$ Further, in academic areas, information on mentoring Licensed Practical Nurses earning their baccalaureate degree is available. For example, assessing individual learning obstacles and creating plans to address these; ${ }^{[22]}$ monitoring entrance GPA, ongoing GPA and cumulative GPA; ${ }^{[23]}$ and rigorous preparation classes for national registration examinations. ${ }^{[24]}$

However, there is a "gap" in our understanding of the kinds of mentoring based instructional strategies that work best for these non-traditional students during their practicums. Nurses with experience instructing in clinical areas are a rich resource and the approaches they implement may go unnoticed. Findings from this study, which listened carefully to the voices of nurses directly involved in clinical teaching, will contribute to existing literature on instructional mentoring and will inform nurses interested in mentoring LPNs and other non-traditional students.

As part of an overarching program of research investigating the experiences of one group of non-traditional students and instructors, those involved in an LPN to BN (Licensed Practical Nurse to Bachelor of Nursing) program, 10 experienced Registered Nurse (RN) instructors were invited to discuss the mentoring approaches they implemented during clinical practicums. In some jurisdictions, Licensed Practical Nurses (LPN's) are also known as Registered Practical Nurses (RPN's) and Licensed Vocational Nurses (LVN's). In some regions, the word "mentor" denotes the practitioners in clinical settings who support and precept learners in practice. Although definitions of mentoring continue to be developed, ${ }^{[25-27]}$ in this study, the term "mentoring" refers to the following definition accepted by the American Nurses Association: "Mentoring is a broad caring role that encompasses formal or informal supporting, guiding, coaching, teaching, role modeling, counseling, advocating, networking, and sharing". ${ }^{[28]}$ The instructors who participated were employed by the university to facilitate learning for small groups of students during their clinical practicums.

The objective of the study was to describe effective mentoring approaches that instructors in a Post Licensed Practical
Nurse to Bachelor of Nursing (Post LPN to BN) program used to support students' learning during their instructor led clinical practicum courses. This article reports research findings where clinical instructors shared practical, everyday mentoring strategies that helped support their students towards success. The strategies will be of interest to nurse educators and practitioners involved in the clinical education of non-traditional students.

\section{METHODS}

\subsection{Research approach}

\subsubsection{Conceptual framework}

The study was grounded in constructivist student centered epistemology ${ }^{[29,30]}$ and incorporated ideas from Laurent Daloz's model of mentoring. ${ }^{[13,14]}$ Daloz asserted that in order for mentoring activities to enhance learning, the dimensions of support (affirming activities); challenge (generating dissonance and cognitive tension); and vision (envisioning future outcomes) must all be present. Support alone, although a foundational element in any mentoring relationship, is incomplete. When learners feel a high sense of support, but a low sense of challenge and/or a low sense of vision, development and progression does not occur. Similarly, when support and vision are low, but feelings of challenge are high, learners can feel intimidated, unmotivated and often withdraw completely. Alternatively, when support, vision and challenge are all low, learners simply remain in a static state. ${ }^{[13,14]}$ Therefore, in this study, the dimensions of support, challenge and vision were used to help organize the interview data.

\subsubsection{Design}

A qualitative descriptive design guided the study. A qualitative descriptive design provides a clear, straight description of experiences, perceptions, or events using language from data collected; usually involves minimally or semi structured interview guides; and uses low inference interpretations to summarize findings into themes or categories. ${ }^{[31-36]} \mathrm{Re}$ searchers remain close to the surface of the data and describe events from participants' own viewpoints. ${ }^{[37,38]}$ The goal of descriptive research is to communicate directly with participants and search for precise accounts and rich descriptions of the experiences, events, and processes that most individuals would agree are accurate. ${ }^{[31,33,39]}$ Two main elements consistent with qualitative descriptive research are that researchers learn from participants and their descriptions and then use this knowledge to influence interventions. ${ }^{[31,34]}$

\subsubsection{Setting and participants}

The study was implemented at a Canadian open university offering a post LPN to BN program available to students 
from across the country. Letters of invitation to hear more about the study were e-mailed to the 15 full-time and contract faculty who were instructing in practicum components of the program. These faculty all had five or more years of teaching experience. 10 faculty members expressed interest and agreed to participate. Most of the participants were employed primarily in clinical practice and only taught with the university on a contract basis. Full ethical approval was granted by the university's Ethics Review Board.

\subsection{Data sources}

Data sources were 10 digitally recorded, transcribed telephone interviews with these participants. The interviews were approximately an hour long and conducted by a research assistant who was not employed by the university and who was not in a position of "power over" participants.

In keeping with a qualitative descriptive research design, a minimally structured interview guide, which allowed the interviewer to explore and delve further into participants' comments about their mentoring approaches, was used. The following six questions were used to guide the interviews:

(1) Let's begin with your background. Please share a bit about your teaching experience.

(2) What does the concept of "mentoring" mean to you? What is a mentor?

(3) Talk about the kinds of mentoring approaches you are implementing in your clinical practicums.

(4) Can you think of ideal mentoring approaches you believe in and would like to implement?

(5) How might you describe your mentoring in relation to being mentored yourself?

(6) What barriers and challenges have distracted from implementing mentoring approaches?

\subsection{Data analysis}

The interview transcripts were analyzed for themes initially using line by line coding to group participants' phrases and conversations (indicators) into meaningful qualitative units or categories of concepts. ${ }^{[40]}$ Daloz's ${ }^{[13,14]}$ emphasis on the importance of support, challenge and vision in mentoring were considered as each category emerged. Next, in keeping with naturalistic inquiry, these categorizations led to the development of overarching themes. ${ }^{[1]}$ The transcripts were thoroughly read and re-read. To achieve investigator triangulation, the primary researcher and research assistant met regularly to discuss interpretations. Member checking, or sharing interpretations of the findings with participants, ensured trustworthiness and authenticity.

Published by Sciedu Press

\section{Results}

\subsection{Theme one: Support students by validating their in- dividual strengths}

Participants frequently mentioned the sincere respect they felt for their students. Comments such as "Some of my students know far more than I do in their areas of practice" were common. In particular, they remarked on how the LPN to BN students brought valuable nursing experiences to their practicums. One participant stated: "[non-traditional] students are more goal-directed than the young ones [meaning traditional students] who maybe don't know exactly what their goals are in life or in their career." Another participant remarked on how their students "are nurses who [are already] providing care to people who are struggling or troubled in some way. So, you can always draw on that."

Participants also often talked about the difficulties their students were facing and the perseverance needed to overcome these. Students in the program are required to attend designated clinical sites for their two to four-week practicums. As a national program at an open university, students come from across the country. For many, attending practicums meant temporarily relocating to a new city, leaving behind their families and full-time employment. In one participant's words: "they have kids, they have families, they've been around the block a few times and lots of them are new to the country and they are still learning English. Just getting to clinical is an ordeal." As an example, another participant described a new mum who relocated with her infant, so she could continue breastfeeding. The students' mother also left her family and full-time employment to care for the infant while the student attended clinical.

Several participants emphasized the importance of first recognizing and then validating students' commitment to advancing their education. In turn, "letting students know that you understand, or at least can try to understand what they are going through [demonstrates support]. When instructors understand their students' circumstances, they can more effectively identify their special strengths." As one participant expressed: "[non-traditional] students are extremely taxed. They are very tired, and they are juggling a lot of things to get through school. But, that all points very loudly to the tremendous tenacity and strength they have within themselves. So, when they are struggling or having hard times, find out what they have done in the past to succeed. Validate what they've done to get this far. That's what you do to get them through."

Participants further validated strengths with an inherent belief that their students could and would accomplish both their personal objectives and those designated by the program. Fostering a sense of pride was an important element of men- 
toring for several participants. In her explanation of what she believed a mentor was, a participant stated:

"a mentor is someone who can mirror back the greatness in others. So, if my students leave me feeling profoundly proud of who they are and really certain of their potential, then I've done a great job. That's what will take them forward, what will make them want to keep learning, what will make them want to care for people. Not me, not the little morsel of education I give them. I want them to leave [this practicum] feeling fantastic about their particular contributions. I have a strong belief that that each student that I meet has specific and unique potential in themselves that only they can share. There's no one else on earth who will share and be just like them. So, what I really want is for them to see is their own kind of greatness."

In essence, the experienced clinical instructors in this study suggested that effective mentoring support includes knowing the difficulties students face and validating the individual strengths students themselves draw on to succeed. Strategies they suggested for validating individual strengths included providing students with one-to-one discussion times where they could explain what they were doing well; setting a positive, success oriented tone during post conferences; and ensuring self-evaluation opportunities included a balance of strengths as well as areas to grow.

\subsection{Theme two: Challenge students by building on those strengths}

With an understanding of their students' individual strengths in place, participants expressed ways they could incorporate Daloz's ${ }^{[13,14]}$ mentoring dimension of "challenge" (introducing cognitive tension) to build on those strengths. The following comments typify how participants challenged students to stretch and grow beyond their personal best. "I don't tend to compare them too much to each other, or to generic [meaning traditional] students. I just want them to really know more when they leave than when they came to the unit." "... I like them to think about their own progress. They are all quite varied in where their strengths are. But they all have strengths and skills, so we work together to add in what else they need to know to meet the competencies."

One participant approached the mentoring dimension of challenge by setting high expectations. She believed her students "can succeed and they will succeed". In her view "I don't want them to be average - I want each student to be exceptional. Even when someone could pass or demonstrate the competencies on the first day - they need to work towards being really exceptional for who they are and what they have to offer."
Several participants introduced challenge into their supportive mentoring by involving students' peers. During post conference, one participant routinely engaged in the following round robin discussion activity. "Name one thing that you're really proud of and that you think went great. [Then] name one thing you think kind of wasn't that great. We do that as a group and the others offer their ideas. It shouldn't all be about what went well." Another participant mentioned how she "does everything" to make sure students "don't feel alone. I have them work in pairs and part of that is to tell each other what it really hard for them and what they are doing about making it not so hard."

Specific strategies that participants described included providing examples of well-written charting. This strategy was especially valuable to English as a Second Language students. When students compared their charting drafts to the examples, they could self-identify points that were missed before actually entering information on patient/client charts. Another strategy was to have students create mind maps to illustrate what they knew about and had researched for their patient/client. The instructor reviewed each of the mind maps and identified concepts that were incomplete. As students developed and added to their mind maps, a succinct visual of how they were overcoming the challenges of what they did not know emerged. Unlike more cumbersome written descriptions of patient/client conditions, the diagrammatic mind maps communicated student progress at a glance.

\subsection{Theme three: Create vision with links to future prac- tice}

All of the participants remarked on the importance of asking students about the areas where they hoped to practice in future. Knowing where students hope to work after graduating made it much easier to create links between competencies required in the future, with those they were achieving in their present placement. As adult learners, non-traditional students are likely to question why they are required to learn a skill or master a concept in a clinical area, when they do not believe they will ever work in that area. The vision of "yes - you will need this later and here's why" helped guide students towards outcomes that felt relevant to them. In one instance, when students commented on how they would not be working in mental health, a participant described how she "told stories about using mental status exams and other psych/mental health skills in all kinds of other areas. Then they could see they would actually use [mental health skills]."

"Getting them to think outside their comfort zone" was the expression two participants used when commenting on how they incorporated challenge into their mentoring. Another participant talked about inviting students to imagine them- 
selves practicing in their desired area, and successfully implementing a needed skill.

Strategies for creating vision that participants suggested included encouraging students to initiate a clinical "keeper file" of information they thought would be useful in their future practice. Students could add to this personalized file as they attended different practicums. Another visioning strategy was to create an online group discussion forum. Each week, the instructor posted a competency and required students to comment on how mastering the competency would affect their future practice. They were also required to respond to a minimum of two of their peer's posts. This exchange of information and interactivity occurred outside their time in the clinical area and helped student groups introduce the idea of visioning into their discussions.

\section{Discussion}

Although none of the participants held advanced degrees in education, their experience and tacit knowledge equipped them with the capacity to mentor their non-traditional students with support, challenge and vision. Their processes of supporting students by validating their individual strengths reflected an empathic understanding of the difficulties their students faced. By tapping in to what students themselves were doing to overcome these difficulties, they communicated a deep and affirming level of support. When they introduced challenge, they did so by identifying students' individual strengths and then extending and building on these. They not only wanted their students to achieve required competencies, they wanted them to go beyond their own personal best and excel. By knowing the specific practice areas their students hoped to work in, the participating clinical instructors were able to create vision that was personalized and meaningful for each student. In order to attend their practicums, the LPN to BN students all made significant sacrifices, including leaving their employment for weeks at a time. Creating links between the skills and concepts they were required to master in a practicum area they may not express interest in, and an area they felt passionate about and planned to practice in, could help students feel their time was well spent.

Joseph Chen asserted that most post-secondary programs are youth-centric, generally designed for younger students and neglect non-traditional students, viewing them as "invisible." "[7] Participating instructors in this study, who worked in a program only available to non-traditional students, seized the opportunity to find simple, practical approaches that begin to address this deficit. Although they could not do anything about the time students were required to be away from their work and families, the instructors found ways to genuinely affirm their sacrifices. By personalizing learning,

Published by Sciedu Press the instructors were able work collaboratively to build on what students already knew.

The mentoring strategies that the experienced clinical instructors in this study described can readily be implemented in a variety of different practice areas. Nurses in clinical practice who also take on the role of practicum instructor may have limited opportunities to gain an in-depth understanding of educational approaches that can work well with non-traditional students. However, by simply grounding their instruction in an unwavering commitment to building on their students' strengths, less experienced nurses can make a very special difference.

A limitation of the study is that students' perceptions of the instructional mentoring approaches were not explored. Plans to do so are place. However, as participants described their students' progress, the pride in and commitment to supporting students' accomplishments was expressed clearly in their tone of voice and word choices. During the interviews and when reading the transcripts, the researchers made an assumption that students may also have sensed that their instructors felt proud of them. When Rylance, Barrett Sixsmith and Ward explored the mentoring relationship, the area where nurse mentors gained the most satisfaction was to see their students' progress. ${ }^{[42]}$ Similarly, in the present study, participants appreciated seeing their students succeed and excel. They wanted to share the approaches that they found valuable with other nurses who provide instruction to students in clinical areas.

\section{Conclusions}

Findings from this study indicated that experienced clinical instructors mentored non-traditional nursing students by supporting and validating their individual strengths; challenging them by building on those strengths; and creating personalized vision by linking their present activities to competencies needed in the areas where they hoped to work. Specific support strategies included knowing the difficulties their students were facing as well as the unique ways they were seeking to overcome them. The instructors intentionally created activities for identifying and then building on students' strengths during one-to one discussions, post conferences, evaluation processes and online discussions when away from the clinical area. They challenged their students with opportunities to use example chart entries to correct drafts of their own charting. They also challenged students to visually represent concepts on mind maps, which the instructors used to identify areas where a deeper understanding was needed. In preparation for their future practice, instructors invited students to initiate a personally meaningful filing system for the clinical knowledge and skills they would put to good use 
later.

Although post-secondary institutions may not have fully adapted to the educational needs of non-traditional students at the administrative and curricular levels, clinical instructors may be doing so at a grass roots level. As participants in this study illustrated, clinical instruction grounded in a mentoring approach that builds on the strengths students bring to their learning shows promise. Continuing to find ways to support, challenge, and provide vision to students is both a challenge and an opportunity for nurses who instruct clinical practicums.

\section{CONFlicts OF INTEREST Disclosure}

The authors declare they have no conflicts of interest.

\section{REFERENCES}

[1] Grabowski C, Rush M, Ragen K, et al. Today's non-traditional student: challenges to academic success and degree completion. Inquiries Journal/Student Pulse. 2016; 8(03).

[2] Olin J. Non-traditional nursing students take nontraditional pathways. RNCentral. 2011. Available from http://www.rncentral.com/blog/2011/non-traditional -nursing-students-take-non-traditional-pathways/

[3] Ross-Gordon J. Research on adult learners: supporting the needs of a student population that is no longer nontraditional. Peer Review. 2011; 13: 1. Available from: https://www.aacu.org/publica tions-research/periodicals/research-adult-learner s-supporting-needs-student-population-no

[4] Spies C, Seale I, Botma Y. Adult learning: what nurse educators need to know about mature students. Curationis. 2015; 38(2): 7 PMid: 26842085. https://doi.org/10.4102/curationis.v 38i2. 1494

[5] Sutton J. Anticipating concerns of the adult leaner: accelerated paths to a degree and intrusive advising. Community College $\mathrm{J}$ Res Pract. 2016; 40(5): 456-458. https://doi.org/10.1080/10668926.2 015.1059779

[6] National Center for Education Statistics. Demographic and enrollment characteristics of nontraditional undergraduates: 2011-12. US Department of Education. 2015. Available from: https://nces .e d.gov/pubs2015/2015025.pdf

[7] Chen JC. Nontraditional adult learners: the neglected diversity in postsecondary education. Sage Open. 2017; 7(1). https ://doi . or $\mathrm{g} / 10.1177 / 2158244017697161$

[8] Melrose S. Gordon K. Overcoming barriers to role transition during an online Post LPN to BN program. Nurse Educ Prac. 2011; 11(1): 31-35. https://doi.org/10.1016/j.nepr.2010.06.002

[9] Suva G, Sager S, Mina ES, et al. Systematic review: bridging the gap in RPN-to-RN transitions. J Nurs Scholarsh. 2015; 47: 363-370. https://doi.org/10.1111/jnu.12147

[10] Tower M, Cooke M, Watson B, et al. Exploring the transition experiences of students entering into preregistration nursing degree programs with previous professional nursing qualifications: an integrative review. J Clin Nurs. 2015; 24: 1174-1188. https: //doi.org/10.1111/jocn. 12756

[11] Melrose S, Miller J, Gordon K, et al. Becoming socialized into a new professional role: LPN to BN student nurses' experiences with legitimation. Nurs Res Prac. 2012; 2012(4): 946063. https //doi.org/10.1155/2012/946063

[12] Melrose S, Wishart P. Resisting, reaching out and re-imagining to independence: LPN's transitioning towards BNs and beyond. Int J Nurs Educ Scholarsh. 2013; 10(1): 107-113. https ://doi.org/ 10.1515/ijnes-2012-0033
[13] Daloz L. Effective teaching and mentoring. San Francisco: JosseyBass; 1986.

[14] Daloz L. Mentor: guiding the journey of adult learners. Wiley: New York; 2012. PMid: 22397675.

[15] Ferrari J. Mentors in life and at school: impact on undergraduate protégé perceptions of university mission and values. Mentoring \& Tutoring: Partnership in Learning. 2004; 12(3): 295-305. https://doi.org/10.1080/030910042000275909

[16] Holba AM. From advising to mentoring: Shifting the metaphor. Mentor. 2012. Available from: http://dus .psu.edu/mentor/2012/ 11/advising-to-mentoring-shifting-metaphor/

[17] Smith B. Mentoring at-risk students through the hidden curriculum of higher education. New York: Lexington Books; 2013.

[18] Dorsey L, Baker C. Mentoring undergraduate nursing students: assessing the state of the science. Nurs Educ. 2004; 29(6): 260-265. https://doi.org/10.1097/00006223-200411000-00013

[19] Melrose S. Mentoring online graduate students: partners in scholarship. Educ Prim Care. 2006; 17(1): 57-62. https ://doi .org/10 .1080/1475990X . 2006.11493511

[20] Myall M, Levett-Jones T, Lathlean J. Mentorship in contemporary practice: The experiences of nursing students and practice mentors. $\mathrm{J}$ Clin Nurs. 2008; 17(14): 1834-42. https://doi.org/10.1111/ j.1365-2702.2007.02233.x

[21] Robinson S. Sustaining mentorship for student nurses. Nurs Times. 2013; 109(16): 24-25. PMid: 23697008.

[22] Miller C, Leadingham C. A formalized mentoring program for LPN-to-RN students. Teach Learn Nurs. 2010; 5(4): 149-153. https://doi.org/10.1016/j.teln.2010.03.002

[23] Coffey S, Lindsay G, Cochrane M, et al. Making the grade through the front door: evaluation and innovation in a Registered Practical Nurse to Bachelor of Science in Nursing program. J Educ Training Studies. 2016; 4(1): 32-38.

[24] Cook L, Dover C, Dickson M. Returning to school: The challenges of the licensed practical nurse-to-registered nurse transition student Teach Learn Nurs. 2010; 5(3): 125-128. https : //doi .org/10.1 016/j.teln.2010.02.003

[25] Dawson P. Beyond a definition: toward a framework for designing and specifying mentoring models. Educ Res. 2014; 43(33): 137-145. https://doi.org/10.3102/0013189X14528751

[26] Jokelainen M, Turunen H, Tossavainen K, et al. A systematic review of mentoring nursing students in clinical placements. J Clin Nurs. 2011; 20: 2854-2867. https://doi .org/10.1111/j.1365-270 $2.2010 .03571 . \mathrm{x}$

[27] Shaikh AM. Understanding effective mentoring in nursing education: the relational-reliant concept. JOJ Nurs Health Care. 2017; 2(5): 555596. 
[28] American Nurses Association (n.d.). Mentoring definitions [Fact sheet]. Milton, MA. Available from: http://www . anamass.org/ ?61

[29] Melrose S. Constructivism: building on what learners already know. In S. Melrose, C. Park, \& B. Perry (Eds.). Teaching health professionals online: frameworks and strategies. Athabasca, AB, Canada: AU Press; 2013. https : //doi .org/10.15215/aupress/97819 27356654.01

[30] Peters M. Does constructivist epistemology have a place in nurse education? J Nurs Educ. 2000; 39: 166-172. PMid: 10782761.

[31] Neergaard M, Olesen F, Andersen R, et al. Qualitative description the poor cousin of health research? BMC Med Res Method. 2009; 9: 52-55. https: //doi.org/10.1186/1471-2288-9-52

[32] Sandelowski M. Whatever happened to qualitative description? Res Nurs Health. 2000; 23: 334-340. https ://doi .org/10.1002/10 98-240X (200008) $23: 4<334:$ :AID-NUR9>3 . 0 . CO ; $2-G$

[33] Sandelowski M, Volis C, Knafl G. On quantitizing. J Mix Meth Res. 2009; 3: 208-222. https://doi.org/10.1177/155868980933 4210

[34] Sandelowski M. What's in a name? qualitative description revisited. Res Nurs Health. 2010; 33: 77-84. PMid: 20014004.
[35] Kim H, Sefcik J, Bradway C. Characteristics of qualitative descriptive studies: a systemic review. Res Nurs Health. 2016; 40: 23-42. https ://doi.org/10.1002/nur.21768

[36] Lambert V, Lambert C. Qualitative descriptive research: an acceptable design. Pac Rim Int J Nurs Res. 2012; 16(4): 255-6.

[37] Atkinson J, Delmont S. In the roiling smoke: qualitative inquiry and contested fields. Int J Qual Stud Educ. 2006; 19: 747-755. https : //doi.org/10.1080/09518390600975974

[38] Creswell J. Qualitative inquiry and research design. Choosing among five approaches. 3rd ed. Thousand Oaks, CA: Sage Publications; 2013.

[39] Berg B. Qualitative research methods for the social science. 5th ed. Boston: Pearson Education; 2004.

[40] Chenail R. Conducting qualitative data analysis: reading line-byline, but analyzing by meaningful qualitative units. Qualitative Report. 2012; 17(1): 266-269.

[41] Lincoln YS, Guba EG. Naturalistic inquiry. Newbury, CA: Sage Publications; 1985.

[42] Ryance R, Barret J, Sixsmith P, et al. Student nurse mentoring: an evaluative study of the mentor's perspective. Br J Nurs. 2017; 26(7): 405-409. https://doi.org/10.12968/bjon.2017.26.7.405 